\title{
The concept of "ba": A new path in the study of knowledge in firms
}

\author{
FRÉdÉRIC CREPLET*
}

\begin{abstract}
In this article we present a relatively novel concept: the "ba". This concept was put forward by two authors, Nonaka and Konno (1998), who showed that the "ba" - a form of interaction "place" - was a foundation for the creation of knowledge in an organisation. We believe that this space plays a decisive role in the study and description of knowledge management in firms and that it can be used in many fields of research. Because it is a multi-organisational, multipurpose, etc. concept, its contribution is significant. Our presentation of this concept will be based on the works of Nonaka and Konno (1998), but we will also examine the main themes arising from the theoretical movements dealing with knowledge in organisations. Moreover, we are also putting forward a framework of study related to this concept, and a definition of the main possible forms of "ba".
\end{abstract}

Classification Codes: L20, L21, L23, M11, M12, M13, M14.

\section{Introduction ${ }^{1}$}

Two Japanese authors, Nonaka and Konno (1998), known for their various works on knowledge management, introduced, in a recent article, a new concept in knowledge management: the "ba". They describe the "ba" as a "shared space", a form of "learning foundation" in its own right, a place of interpersonal interactions which generates knowledge. A number of mechanisms within it, ranging from communication, learning and reflection, to the codification of elements and the diffusion of knowledge, etc. combine, in a given context, in order to create knowledge which, depending on the perspective, has an individual and/or collective nature.

\footnotetext{
* BETA-Louis Pasteur University, 61, avenue de la Forêt Noire, 67070 Strasbourg, Cedex 07, France. E-mail: creplet@cournot.u-strasbg.fr

Keywords: Creation of knowledge, learning process, routines, cognitive cards, organizational memory, knowledge management.

${ }^{1}$ I would like to thank Professor Patrick Cohendet for his advice and his attentive reading of this article. This work has benefited from the financial support of the European Programme TIPIK dedicated to knowledge codification. The author would also like to thank all the BETA researchers who have participated in this programme, for their comments and suggestions. The authors are fully responsible for any error or omission.
} 
The new contribution of Nonaka and Konno to the study of knowledge in firms is quite considerable. However, several points need to be clarified. Several mechanisms can be mentioned, such as learning and more generally, knowledge creation-related mechanisms and their relation to a context. Indeed, several authors show the importance of the context in the creation of individual and collective learning processes in an organisation (see below); in most cases, however, only the favourable or unfavourable characteristics of these mechanisms are examined. The "ba" is thought to have a more global, or even a more unifying impact. It is believed to be a new link in the understanding of knowledge mechanisms in firms and by extension, many phenomena that occur in firms. In this article we shall present the "ba" and try and define its main advantages.

First of all we will present the characteristics of this concept by describing its main properties as well as its implications. Secondly, we will present the main forms of "ba". This concept is not unique as such; it can be approached from different angles and can open up new prospects to organisations. We will then attempt to look beyond the contributions of Nonaka and Konno but will also stress the importance of the forms that they have emphasised.

\section{The "ba": A foundation for knowledge-related mechanisms}

The concept of knowledge can have different connotations according to the perspective from which it is examined (see Polanyi, 1958 and 1966; Baumard, 1999). A cognitivist, for example, would define it as a belief that is true and closely linked to specific mechanisms (Richard, 1995): interpretations, representations or perhaps memory. Since Socrates, different philosophical movements have tried to characterise it (Besnier, 1996); some researchers have tried to differentiate it from information (Cohendet, 1997 and Cohendet and Llerena, 1999), while others have tried to define it, for instance, according to the constraints specific to the market and to the organisations that are part of it, etc.

The concept of knowledge - in order to exist - requires that one or several human agents situated in a context or in a given environment, be taken into consideration. The "ba", which is comparable to a learning platform, is in keeping with this reasoning. Our objective is to define this place and to describe its significance.

\subsection{Definition of the main key concepts}

The concept of "ba" was introduced and defined by Nonaka and Konno in an article entitled "The Concept of "Ba" - Building a Foundation for Knowledge Creation" (1998). They described it as follows: "the concept of "ba" can be considered as a shared space for emerging relationships. It can be a physical (an office, etc.), virtual (e-mail, teleconference, etc.), or mental (shared experiences, ideas, ideals) space or multiple combinations of these spaces". They add: "we consider the "ba" as a shared space which is used as the foundation for the creation of (individual and/or collective) knowledge".

This definition opens up multiple perspectives; indeed, this space appears to be favourable to the emergence of phenomena, that is of relationships. According to the authors, 
these are not just simple interpersonal interactions; on the contrary, the authors presuppose that the "ba" contains the "necessary information" for the creation of both individual and collective knowledge. Thus, this context full of knowledge, is believed to govern to a large extent the above-mentioned interactions. Moreover, with regard to the diversity of the examples given, these "places" could be identified in numerous organisations: a project team, a specialised team, a department in a firm, etc. In many cases, a group of individuals has various skills, that is, know-how and/or knowledge that Nelson and Winter (1982) call "repertoires". Nonaka and Konno believe that the exchanges between the different members confer an increase in knowledge and that the "ba" is therefore a kind of intermediary state that is in constant evolution and which, according to the situation, has a temporary or permanent character.

According to Nonaka and Konno, this state has boundaries which determine the exact nature of all knowledge. Indeed, they add that within its boundaries (which can be perceived as physical or entirely virtual), knowledge has an "intangible" nature, whereas outside of them, knowledge becomes information, which can be "communicated independently from the "ba". It is then found in the media or in networks. It is a tangible asset". This remark is in keeping with the various studies of Atkinson and Stiglitz (1969) and more recently of Saviotti (1998) which show that "knowledge has a local nature" whereas information can be separated from its context, and is equivalent, according to Boulding (1956) to "a flow of messages". The existence of these boundaries not only implies that knowledge can become information and be codified - as was underlined by Cowan and Foray (1997) in another context - but also that if it is not "used during a specific period of time and in a given space, it no longer has any value" (Nonaka and Konno, 1998).

This last remark leads us to consider certain fundamental properties of the "ba"; the authors in their article do not allude to them directly. The first of these properties is the existence of a "language that is common" (Habermas, 1987) to the different individuals interacting in this space, and which guarantees that exchanges take place (through speech during a meeting, through written communication in an email, etc.).

The "ba" can - under certain conditions - become a space governed by the principles of self-organisation. Indeed, it can, thanks to each member's personal experiences, constantly adapt to many specific contexts. The "ba" is thus a "vehicle of learning" guided by consensus and persuasion procedures in which several "cross-fertilisations" occur (see for instance Cohendet et al., 1997). Thus, the "ba" is thought to allow what Koenig (1997) called a "better confrontation and structuring between agents who are used to mobilising their skills in an independent manner".

Lastly, the "ba" can be the place where a form of organisational memory is created, a place within which individual knowledge is not necessarily used continually. The "ba" can generate formalised elements (knowledge base, journals, etc.), forms of memory in their own right. This memory can thus be described as "an acquisition/ retention/ storage/ archival storage and restoration/ restitution/ satisfactory implementation of the accumulated knowledge" (Divry and Lazaric, 1998). It makes it possible, among other things, to establish a certain amount of industrial knowledge, which - according to Hatchuel and Weil (1992) - is sometimes subject to chronic instability resulting from change and variety. 
The "ba" has another significant aspect: it is composed of different forms of knowledge. Indeed, this space can give rise to both tacit and codified knowledge which, as we have already seen, may be individual or collective. Tacit knowledge was described mainly in the works of Polanyi (1966) who believes that tacit knowledge is personal, and closely related to a given context, and that it is therefore difficult to transfer or even to formalise. It can materialise, in an organisation, as know-how or even as organisational routines defined "as interaction models representing efficient solutions to particular problems" (Coriat and Weinstein, 1995). As far as codified knowledge is concerned, it can be "more precisely described and specified, according to Cowan and Foray (1997), in terms of content and intellectual properties"; Nonaka and Takeuchi (1995) define it as sequential and digital knowledge based on rationality. Polanyi (1966) identifies the role played by tacit knowledge in the use of explicit knowledge. In this regard he claims that: "tacit and codified knowledge "cannot be entirely differentiated. Whereas tacit information can be acquired per se, explicit knowledge depends on a largely tacit comprehension and application". We shall not define these different kinds of knowledge any further, as we have merely tried to indicate what forms of knowledge could emerge in the "ba".

The first elements that we described highlight a number of overlapping layers in the "ba": the first layer could be compared to a space [see above], the second is like a social matrix composed of related individuals and lastly, the third layer represents a given goal. We will not put forward - at this stage of our research - any more levels, although we could quite possibly emphasise others.

These elements open up to us a different interpretation of knowledge creation and call for various theoretical concepts. We therefore wish to show that this concept is related to the existence of several fields of research.

\subsection{Presentation of what is at stake as regards the concept of "ba"}

The main terms of the definition of the concept of "ba" provided by Nonaka and Konno (1998) and of the possible comparisons with elements existing in literature, lead us to widen our focus. The first aspect we wish to discuss resides in the difficulty of dissociating this concept from that of "routine".

Coriat and Weinstein claim that "the agents' actions within the firm can only reach some degree of coherence if routines bind the different behaviours together". As was mentioned above, this idea presupposes the existence of interactions. Nelson and Winter (1982) use the term routine "in a highly flexible manner, just as the word "programme" is used in a conversation about computer programming. It refers both to a repetitive model of activity for a whole organisation, and to an individual skill". Thus routines are believed "ideally" to enable individuals to react automatically when faced with change; moreover they are thought to be the definite consequence of a number of learning processes that include large "fields of tacit knowledge"; the routines are thus difficult to codify. Dosi (Cohen and Dosi, 1995) shows that one of their main characteristics is their being "dependant on a context". Winter (Cohen et al., 1995) thinks that this context has a physical dimension (a factory, etc.) and that it is characterised per se by motivations and relationships. Several categories of routines can be identified: Nelson and Winter (1982) 
differentiate routines related to "satisfacing", from innovating routines directed towards "search" behaviours.

At first, the concept of "routines" appears relatively close to the "ba" in as much as several similar phenomena pre-exist. However, whereas routines have a highly automatic nature, the very essence of the "ba" does not seem to. Moreover, according to evolutionists, they do not have any "historical or social content" (Coriat and Weinstein, 1995); this is a determining element - within the "ba" - that we have already mentioned and that we will discuss further in our description of several examples.

On the basis of these numerous observations, we can assert that there is a certain dissimilarity between these two concepts, which is not to say that they are entirely different. Thus, the concept of routines could be considered, in such "shared spaces", as a knowledge mechanism; it could be part of the above-mentioned social matrix, in which case the "ba" could directly influence the existing "routines", inasmuch as it would govern their context. It would probably result in routines with various characteristics depending on its nature [see below]. Thus, innovating routines would, for example, have disparate functioning modes; moreover some routines could be present in several "ba". These hypotheses enable us to ascribe a different significance to the study of the "ba" and to link various questions to it: innovation, reactions to change, etc. One possibility could also be to describe the "ba" - depending on its characteristics - as a "specific asset" (see for instance Baudry, 1995) in the sense used by Williamson (1994), as evolutionists do with "routines" (see Coriat and Weinstein, 1995).

The concept of "ba" can also be related to the existence of shared cognitive cards that are coupled with its other characteristics (learning, memory, communication, etc.). This idea which, in another context, is supported by Llerena (1997) implies that they are necessary in order to "ensure that the activities carried out by each member or by each unit of the organisation are coherent and co-ordinated. These cards enable individuals to share a same vision of the reality of the organisation, that is of its internal functioning and its relationship with the environment". In addition to these cards, inter personal cognitive co-operation mechanisms could be found within the "ba". These mechanisms enable organisations to collect or even to confront representations and other interpretations generated by the different individuals. Moreover, (according to Llerena, 1997), these co-operation mechanisms initiate the creation of new collective knowledge "through a combination of mental (individual) models, but also through the co-evolution of individual knowledge".

Before drawing our conclusions regarding the implications that we have underlined, we will spend some time discussing the possible limits or dysfunctions that could affect this space. The latter is a place of exchange and relationships of various kinds; in our opinion, one of the typical risks could be the development of information asymmetries between some of the members, arising from conflicting interests, power struggles, or perhaps opportunism. More specifically, it is conceivable that individuals might operate completely different mechanisms, shown in the difference between what they say ("espoused theory") and what they actually do ("theory in use") (Argyris and Schon, 1978). Individuals - in their relationships - can also fall victim to differences of interpretation; the main consequence is the emergence, or even the diffusion of mistaken or incomplete knowledge. In such a space, it is possible that some individuals develop 
"defensive routines" (Argyris, 1995), in seeking to protect themselves when change occurs. This implies that it is necessary - for the manager - to implement incentive or even monitoring systems; Cohendet et al. (1997) suggest the possible use of governance mechanisms, the aim of which is to "control the learning dynamics" within a context of collective behaviour. These governance mechanisms could also be applied, should it be necessary, to the co-ordination of the different "ba"existing within the firm. And finally, certain individuals might find it difficult to access knowledge and therefore to access other individuals, or they may even experience problems in terms of their capacity to assimilate knowledge. (Cohen and Levinthal, 1990); this points to the existence of an obstacle hindering the construction of the "ba" and leads us to assume that the constitution of the "ba" is not always necessarily optimal. This optimisation is in itself an aim.

Other elements can have a negative impact on this "shared space"; several authors such as Reix (1995), or even Foray and Lundvall (1997) have described the drawbacks of tacit knowledge or even of codified knowledge in a specific context (presence of an omnipresent technical and local dialect that hinders change, etc.). These elements must be taken into consideration because they represent the desired result: the creation of tacit and /or codified knowledge.

Lastly, we have our doubts as to whether all organisations are always capable of developing such spaces and as to whether these spaces are essential and sufficient for the creation of all organisational knowledge.

Having characterised the main features of the concept of "ba", we will now describe its main forms. For this purpose we will propose a theoretical framework, and then use the main propositions of Nonaka and Konno (1998) in the framework of Nonaka and Takeuchi's hypothesis (1995) of a model of the creation of organisational knowledge, and lastly we will make use of the different empirical cases that illustrate our presentation.

\section{From the main forms of "ba" to the concept of communities of practice}

This concept appears - because of the way it is presented - to be relatively general. It is necessary to try and give a more detailed explanation of the different forms of "ba" that can be found in an organisation. The concept of "ba" has a number of determinants that promote its composition, or even its development; the main determinants are the management and the modes of knowledge conversion. After describing the forms of "ba" related to these conversion modes, several other forms will be introduced and collated with the concept of community of practise. Lastly, and in order to illustrate these different points, we will present empirical cases.

\subsection{Proposition of a theoretical corpus: The determining role of management and of knowledge conversion modes}

This "shared space" clearly has a collective scope, inasmuch as a number of individuals interact in one or several contexts. Thus, in our opinion, the main determinant is the type of management practised by the different people in charge of the organisation. 
This management may have different attributes: it could concern both the management of individuals in a place, and the effective monitoring of knowledge resources available to the manager. In the first case, the manager (depending on the scale, this responsibility can be held by a middle or senior manager or by an executive) must promote a context that enhances the development of exchanges, that gives a degree of autonomy to individuals and, more generally, that is favourable to the decentralisation of responsibilities (see Ingham, 1994). As a consequence, the manager will also have to co-ordinate the different groups or "ba". Marengo showed in 1993 (quoted by Cohendet, 1997), through simulations, that local learning processes could be efficient as long as the different hierarchic levels had the ability to co-ordinate them. The manager must therefore promote, delegate, encourage and co-ordinate these different spaces. The second possible type of management is more specific inasmuch as its role is - according to Nonaka and Konno (1998) - to "manage the emergence of knowledge, [...] with visionary propositions (role of the mind) and an important personal commitment".

The type of management practised has therefore an essential influence on the formation of the different "ba". Moreover, the "ba" directly enhances the creation and diffusion of different categories of knowledge (Nonaka and Takeuchi, 1995). Thus, a "top to bottom" 2 type of management promotes the development of codified knowledge and of conversion modes of the combination and internalisation types; a management of the "bottom to top" type ${ }^{3}$ develops knowledge that is essentially tacit, and conversion modes such as socialisation and externalisation; lastly, a "middle to top and bottom" type of management which - according to these authors - is centred on individuals occupying middle management positions, makes it possible to use tacit as well as codified knowledge and to enhance all the conversion modes proposed by Nonaka and Takeuchi (1995): Socialisation / externalisation / combination / internalisation. These different models of management probably result in different "ba" with various characteristics.

Similarly, Nonaka and Konno (1998) identify several forms of "ba" which fit in with the model of the "spiral of organisational knowledge creation" comprising different stages that are determined by specificities and specific mechanisms. As the spiral builds up, the established dynamic generates major evolutions in the organisation inasmuch as knowledge, which was originally held by a limited number of individuals, is modified and diffused more widely into numerous strata.

The first stage - of this spiral - is similar to a "ba" which is composed of essentially tacit, and therefore personal, knowledge that results from different interactions between individuals with similar or different backgrounds. It is named by Nonaka and Takeuchi (1995) "socialisation", and its related "ba" is called "the original ba". This "ba" is essentially composed of "know-how", defined by Foray and Lundval (1997) as "the skill or

\footnotetext{
${ }^{2}$ Nonaka and Takeuchi indicate that this type of management originates directly from the classic hierarchic model which has developped since Weber and Taylor, and Simon. Knowledge creation is seen here from the Information processing perspective.

${ }^{3}$ One of the characterisitics of the "top to bottom" model is the greater autonomy of the agents. The form of the organisation is horizontal and flat. Knowledge creation comes from individuals and not from groups of individuals.
} 
the ability to do something" (see also Dibiaggio, 1997; von Hippel, 1998; Kogut and Zandler, 1992; Winter, 1987).

The second stage is based on the transformation of all of this tacit knowledge into explicit knowledge which is called "externalisation" and relates to the existence of an "interaction ba". Here, individuals are chosen according to their specific skills in one field; the "ba"under consideration is the result of this selection. "Know who" mechanisms (Foray and Lundvall, 1997) that "generate the information about who knows what and who knows how to do what", are then necessary, as are "Know what" (see Cohendet and Llerena, 1999) or "know why" mechanisms; these mechanisms are sources of questioning and reflections.

The third stage results from the fact that a relatively high number of individuals are grouped into units which are both distinct and interactive; this stage is called "combination". The knowledge is exclusively explicit; it is comparable to information and depends on a language that is known by the majority. According to Nonaka and Konno (1998), this stage fits in with a "virtual world where there is no real place, nor any definite period of time"; they have called this place the "cyber ba". The media through which codified knowledge is diffused from one group to the other (for instance from a research and development department to an industrialisation department), varies, but it is essentially centred on the ICT (information and communication technologies) like the Internet, Intranet (see Ciborra, 1996), etc., which use various tools (Groupware, e-mail, etc.). The ICT have properties which reinforce interaction between everyone's codified knowledge, as they - according to Brousseau and Rallet (1997) - increase the "possibility of processing, transmitting and accumulating" information and allow for a degree of co-ordination.

This hypothesis is highly relevant; however it implies a number of conditions: knowing who has the required knowledge and/or the existence of "know who" mechanisms, the implementation of incentive systems encouraging the diffusion of information and avoiding many dysfunctions (see above) and lastly a necessary standardisation focusing on "the procedures of exchange and processing of information".

The fourth and last stage is called "internalisation"; the codified knowledge - specific to a given field - is converted into tacit knowledge by the implementation, at different levels in the organisation, of "learning through practise" processes. The "ba" related to this stage is called "the exercise ba": the empirical and Cartesian dimensions are brought together in the process. The cognitive patterns of individuals probably play a significant role: their personal background, the interpretations they achieve according to the situations, their knowledge in memory, etc, are decisive. This "ba" - as opposed to the previous one - is not virtual, but material: a set of offices, workshops, etc.; it enables collective knowledge to emerge, which takes the form of organisational knowledge.

Examining the "spiral of organisational knowledge creation" allows one to appreciate the fact that the different forms of "ba" are intermediary states which can have a "generic" or "specific" nature depending on the case, and are more or less temporary, allowing the emergence of varied knowledge, through numerous interactions at different levels (individuals, groups, organisation). This model makes it possible to show that the "ba" is a foundation for knowledge creation. Some people consider it a global or even an "ideal" model; however, it is conceivable that one or the other of these conversion modes 
(socialisation, externalisation, etc.) could be implemented in numerous organisations, in an implicit or controlled manner.

\subsection{Generic and specific "ba" and communities of practice}

Four forms of "ba" are presented above; according to us, they are not only found in Nonaka and Takeuchi (1995)'s model of organisational knowledge creation, but also in many other contexts. However, this approach - real typology of the "ba" - is restrictive and is limited to the categories of knowledge used. Other types of "ba" exist in the firm; we will examine some of them below, from a different point of view.

This last remark leads us to propose several hypotheses as regards their existence and their nature. Indeed, a priori, no element - in Nonaka and Konno's article (1998) informs us about how the "ba" which are not presented in the framework of the spiral of organisational knowledge, interact.

A first hypothesis can be formulated; it relates to the existence of generic "ba" that are not linked - for instance - to a project. This vision is based on the idea according to which a firm, whatever its size, has innumerable shared spaces that have the characteristics mentioned above; a department in a firm can be considered as one of them, inasmuch as the interaction matrix that pre-exists, and the variety of communication mediums generate different aspects of knowledge. The overall organisation of a firm would then consist in all the different "generic ba" that are or are not directly identifiable, and could be related to a "meta ba", similar to a dominating "ba". The second hypothesis suggests the existence of "specific ba" related to an identified goal; a project team is the best example. In such a space, individuals with various experiences and skills interact in order to create implicit or non-implicit knowledge. These "ba" could also be part of the "meta ba".

We now propose another hypothesis: the articulation - within an organisation - of the "generic" and "specific" "ba". It presupposes the intersection of spaces, with a very different type of logic, but which is nevertheless conceivable. This approach is in keeping with a previous article written by Nonaka and Konno (1993), where the authors presented the concept of "hypertext organisation", which is a synthesis of a conventional bureaucratic structure with project teams, whose members always originate from the "system of the firm", i.e. from the different departments or units. This approach is only a hypothesis; however it enables us to suppose the existence of different kinds of "ba" that are connected within the organisation. The philosophy, the management and the goals of each "ba" would probably diverge, but they would all remain, in essence, a "foundation for the knowledge creation".

In addition to this approach, we could also attempt to relate these other forms of "ba" to the concept of communities of practice introduced by Lave and Wenger (1991) and by Brown and Duguid (1991).

These authors showed how - within an organisation - more or less informal groups are formed. These groups of individuals evolve in order either to find solutions for particular problems, or to find common objectives. In each case, belonging to a "community of practice" depends on the ability of individuals to provide information that has a real practical value. Wenger (1999) attributes three dimensions to this form of community. 
The first dimension has to do with the mutual commitment of the participants. The second supposes that individuals participate in a "common venture" where different views are discussed, where a common code of practise and a system of mutual responsibility are adopted. The third dimension presupposes the existence of a shared catalogue of common resources produced by the members (routines, sensitivities, artefacts, vocabulary, styles, etc.).

The core of this approach - according to Brown and Duguid (1991) - depends on the interrelation between learning and practise. According to them, many conventional studies on learning tend to separate "learning from working and, more significantly, learners from workers". Basing themselves on Orr's research (1987), they propose, in the framework of the "communities of practice", the use of the "learning-in-working" concept, which is the real driving force behind innovation in the firm. We thus get closer to the notion of "learning by doing" from Arrow (1962) or of "knowing in practise" 4 described by Balckler (1995).

Communities of practice are therefore real immaterial spaces of exchange and knowledge creation (see Snyder and Wenger, 2000). It thus appears possible to relate this structure to the concept of "ba". But, these two concepts do not represent the same dimensions; the "ba" is made up of different layers: from a space (material and/or virtual) to a social matrix. In our estimation, the concept of community of practice is, directly integrated into the social matrix.

Thus, a new interpretation of these two concepts and of their potential interrelation is required. Indeed, Nonaka and Konno (1998) do not mention this particular point; and, considering the different forms of "ba" described above, it is possible that a number of "ba" ("original ba" and "exercise ba") are essentially composed of communities of practice because of the significant presence of tacit knowledge. Moreover, some "ba" have a virtual nature and it is reasonable to believe that these same communities also have a virtual dimension (see Cohendet et al., 2000). In this perspective, the members of this virtual community of practice are agents originating, for example, from a same network (Intranet), that is internal to the firm. Through this medium, they exchange knowledge which has a practical objective, and convert it into their own specific context. In this manner, different learning processes are carried out, at individual and organisational levels.

Lastly, considering what we have found out as regards the forms of "ba" and their relation to the concept of community of practice, we can presuppose that the notion of boundary is part of the definition of the concept of "ba". This boundary is, in actual fact, relatively variable and hardly perceptible. It is as intangible as it is invisible but it is real: a psychological boundary (Anciaux, 1996) which evolves from one intermediary state to another. Lastly, this description highlights several codification processes; according to Divry and Lazaric (1998), they "create common codes which preserve coherence in the firm, but which, in the process, can reduce the total amount of collective knowledge". This explains the implementation - along with this process - of memorisation activities which capitalise a major part of this knowledge, without excluding the tacit part of it".

\footnotetext{
${ }^{4}$ Reference quoted by Coombs and Hull (1998).
} 
These different processes most certainly do incur important costs: the cost of explanation, of tacit knowledge encoding, of diffusion, etc. These costs are incurred as much in the different forms of "ba" which have been described, as in the communities of practise.

Having described several forms of "ba", we now wish to further illustrate our point by presenting examples quoted by Nonaka and Konn (1998) in their article, and by analogy, with different examples present in literature.

\subsection{Illustration of the different forms of "ba"}

First of all, Nonaka and Konno (1998) use the example of specific teams that concentrate, at Sharp's, on projects that are considered as urgent. These teams establish close links with a panel of 600 leading consumers and provide them with as much "tacit as explicit knowledge". Here, according to Nonaka and Konno (1998) the "ba" is situated outside the organisation. The interactions thus take place in an inter-organisational dimension, in a certain manner, whereby, without being physically together, the members of the panel interpret past elements and circulate them as tacit and /or codified knowledge. The determining process - present in the "ba" - is indeed the emergence of this new knowledge. This process then, refers to the existence of many phenomena: the checking of this knowledge, the minimisation of all potential ambiguity ("operational as well as semantic" as qualified by Nelson and Winter (1982)) due to the idiosyncratic nature of some parts of this knowledge, or else, to the use, and preservation of this knowledge.

The second example of "ba" is illustrated by a division of Toshiba that specialises in the promotion of new markets for the firm. This is an across the board department with various technological skills, whose task is to introduce "innovation, challenge and speed into Toshiba's management". The members of this "ba" interact via an intranet network and regular meetings; this team is known by most and plays, in fact, the role of "internal agent that collects and dynamises Toshiba's fundamental knowledge".

The third and last example illustrating the concept of "ba" is the Maekawa firm. Nonaka and Konno (1998) describe this structure as a group of independent firms that each have their own specific products, different technologies and markets. In this firm, there are as many "ba" as autonomous entities; the "ba" therefore function at an organisational level, and are an aggregation of groups and individuals present in these entities. These different shared spaces enable this firm - according to the authors - to grow and innovate.

The intentionally succinct presentation of the different empirical cases, makes it possible to acknowledge that the "ba" can be envisaged in many different contexts and that, every time, it generates new knowledge. This first remark - following this finding brings out the fact that the forms of "ba" presented above can be found in Toshiba, Sharp and Maekawa. Indeed, at Sharp's, the interaction "ba" is present; at Toshiba's and Maekawa's, the four forms of 'ba" are identifiable. At Maekawa's it has an inter-organisational dimension that is similar to a network. In our framework of study, Maekawa's "ba" can be compared to a dominating "meta ba" composed of several "generic ba". At Toshiba's or Sharp's, the identified "ba" could be - according to our hypothesis comparable to a "specific ba". It is also possible to glimpse various mechanisms such as 
organisational and individual learning. Moreover, for Sharp and Toshiba, "double loop learning" (see Argyris and Schon (1978)) can be identified inasmuch as the members of these "ba" try to modify the norms of the organisation, by identifying and correcting the errors that have occurred. Another degree of learning, called "deutero learning" (Argyris and Schon, 1978) can be developed in this framework; in this case, the result is then "coded in individual images and cards and is reflected in the organisational learning practises".

Many of the phenomena and other mechanisms described above are highlighted in these firms. Indeed, concepts such as the co-ordination between the above-mentioned "ba" and the rest of the organisation at Sharp's, Toshiba's or Maekawa are perceptible. Other characteristics are also visible: the existence of a privileged conversion mode related to the "ba" in each firm, the notion of boundaries, that of learning, etc.

The last major element is the fundamental role of the management and leadership of the firm. In each case, without management and leadership, no "ba" would have been formed to generate new knowledge. However, we cannot claim that the emergence of new knowledge in an organisation is intrinsically related to one or several "ba". On the other hand we believe that the role of decision-makers is predominant and determining. Indeed, without a personal commitment and the explicit will and intention to lead the organisation onto a specific path (notion of vision), the different "ba" would not have been formed at Toshiba's, Sharp's or Maekawa's. The same argument applies in the hypothesis of the "spiral of knowledge creation" and maybe even in the several examples given by literature.

For this purpose, we simply need to present elements from the French version of the Nonaka and Takeuchi's book (1997). Several empirical cases were recorded by Inghma (1997); after examining them, we can identify different aspects of the concept of "ba".

The example given by Leroy and Ramanantsoa (1997) describes the analysis of a merger-acquisition which occurred at the beginning of the 1990s between Belin and L'Alsacienne. The authors explain that in this operation, approximately 50 "merger workshops" were created; these workshops focused on the "main functions of the value chain and were required to compare the skills of each firm, and then decide which of them would be retained in the new entity". In their study, they indicate that in these workshops "learning was two-fold"; thus, some organisational routines had to be explained to the different partners and several levels of dysfunction could be identified. Basing themselves on the conversion modes presented by Nonaka and Takeuchi, they identified the following modes: combination ("sharing of the codified knowledge"), externalisation ("verbalisation and formalisation of tacit knowledge") and lastly internalisation based on "learning through experimentation". Considering this example, several similarities can be found between these different workshops and the forms of "ba" presented above. Unquestionably, they possess a "specific" nature. Moreover, "ba" such as the "interaction ba", "cyber ba" or even "exercise ba" can be identified. This empirical case shows that real shared spaces were created and were in turn, the means of creating a large amount of individual and collective knowledge, while at the same time playing a decisive role in the outcome of the process. Moreover, without the determined commitment of the management, such "places" could not have been formed; the determining role of management is once again underlined. 
Other examples - from this book - make it possible to identify conversion processes. Ingham (1997) gives the example of an empirical case having to do with a context of cooperation related to R\&D projects. Examining this case also makes it possible to highlight the existence of "ba" and the many knowledge mechanisms which are attributed to it. He reminds us that without determinants such as the leader's vision and his strategic intentions, the autonomy given to individuals and to the team in question, the organisational learning could not have taken place.

Several forms of "ba" exist; whether they are "generic", "specific" or even "dominant", some of their foundations always seem to be similar; within these "ba" several categories of knowledge, as well as several phenomena, can be identified and emerge.

The wealth of empirical cases present in literature, which can be related to the concept of "ba", proves its relevance and its multi-organisational dimension. It leads one to take into consideration several facts within a same set, a same corpus. It privileges a different - but new - interpretation of knowledge management in organisations.

\section{Conclusion}

In this study, we have discussed the concept of "ba" and have tried to define it in the same vein as the authors', but our aim has also been to develop it further and confront it with several other concepts and/or theories. Thus, starting with Nonaka and Konno's definition of this concept (1998), we have described its determinants, possible properties and limits. In so doing we have always maintained a specific perspective: the "ba" can be considered as a foundation for the creation of individual and/or collective knowledge. Thus, it would appear that this concept intrinsically comprises several mechanisms which can be found in many theoretical movements - related to learning, organisation and even knowledge management. Lastly, different notions such as context, boundaries, memory, knowledge categories, etc., can be identified in such "places". Therefore, we believe that the "ba" is not just a Japanese concept, but that it is applicable to numerous firms, whatever their origin.

This study has also given us the opportunity of examining the "ba" from a different perspective. The main forms of "ba" related to the modes of knowledge conversion have been defined. Each one of them has characteristics, and possibly categories of knowledge that may vary. In addition to this approach two other forms of "ba" have been proposed: the generic and specific "ba". The latter have been confronted to the concept of communities of practice.

Thus, the "ba" offers new dimensions to the study of knowledge in firms, whether it is examined from the individual and/or the collective perspective. However, several fields based on this concept still remain to be explored: the fields related to the diffusion of knowledge and to its consequences on a firm's structure, for example. The concept of "ba" therefore remains open to discussion and research.

\section{References}

Anciaux J.P. (1996) Le savoir en action - Des connaissances à la performance. Les Éditions d'Organisation, Paris. 
Argyris C., Schön D. (1978) Organisational learning: A theory of action perspective. AddisonWesley, Reading.

Argyris C. (1995) Savoir pour agir, surmonter les obstacles de l'apprentissage organisationnel. InterEditions, Paris.

Arrow K. (1962) The implications of learning by doing, Review of Economical Study, 26, pp. 166-170.

Atkinson A.B., Stiglitz J.E. (1969) A new view of technological change, Economica J., 79, pp. 573-578.

Baudry B. (1995) L'économie des coûts de transaction, Cahiers Français, No. 272, p. 14.

Baumard P. (1999) Tacit knowledge in organizations. Sage, London.

Besnier J.M. (1996) Les théories de la connaissance. Dominos Flammarion, Paris.

Blackler F. (1995) Knowledge, knowledge work and organization: an overview and interpretation, Organizations Studies, 16, pp. 1021-1046.

Boulding K.E. (1956) The Image. University of Michigan Press.

Brousseau E., Rallet A. (1997) Le rôle des technologies de l'information et de la communication dans les changements organisationnels. In: Économie de la connaissance et organisations. L'Harmattan, Paris.

Brown J.S., Duguid P. (1991) organizational learning and communities of practice: Toward a unified view of working, learning and innovation. Organization Science, 2, pp. 40-57.

Ciborra C.U. (1996) Groupware \& teamwork, invisible aid or technical hindrance? Wiley, New York.

Cohen M.D., Dosi G. (1995) Routines and other recurring action patterns of organizations: Contemporary research issues. Working Paper, Santa Fe Institute (SFI), November.

Cohen W.M., Levinthal D.A. (1990) Absorptive capacity: a new perspective on learning and innovation, Administrative Science Quaterly, No. 35, pp. 128-152.

Cohendet P. (1997) Information, connaissances et théorie de la firme évolutionniste, Économie de la connaissance et organisations. L'Harmattan, Paris, pp. 98-110.

Cohendet P., Kern F., Mehmanpazir B., Munier F. (1997) Structures de gouvernance, routines et compétences : une approche évolutionniste. Mimeo, Béta, Strasbourg.

Cohendet P., Llerena P. (1999) La conception de la firme comme processeur de connaissances, Revue d'Économie Industrielle, No. 88 (spécial), $2^{\mathrm{e}}$ trimestre, p. 215.

Cohendet P., Créplet F., Dupouët O. (2000) Communities of practice and epistemic communities: A renewed approach of organisational learning within the firm. Acte du Colloque WEHIA, Aix Marseille, Juin.

Coombs R., Hull R. (1998) Knowledge management practices and path dependency in innovation, Research Policy, No. 27s.

Coriat B., Weinstein O. (1995) Les nouvelles théories de l'entreprise. Le Livre de Poche, Paris.

Cowan R., Foray D. (1997) The economics of codification and the diffusion of knowledge, Industrial and Corporate Change, 6, pp. 595-623.

Diabiaggio L. (1997) Information, connaissance et organisation. Thèse de Doctorat en Sciences Économiques, Université de Nice Sophia Antipolis, p. 224.

Divry C., Lazaric N. (1998) Mémoire organisationnelle et codification des connaissances, Revue Internationale de Systémique, 12 (1).

Foray D., Lundvall B.A. (1997) The knowledge based economy. OCDE, Paris.

Habermas J. (1987) Explicitation du concept d'activité communicationnelle, Logique des sciences sociales et autres essais. PUF, Paris. 
Hatchuel A., Weil B. (1992) L'expert et le système. Economica, Paris.

Ingham M. (1994) L'apprentissage organisationnel dans les coopérations, Revue Française de Gestion, Janvier-Février.

Koenig G. (1997) Apprentissage organisationnel. In: Encyclopédie de gestion. Economica, Paris.

Kogut B., Zandler U. (1992) Knowledge of the firm, combinative capabilities and the replication of technology, Organization Science, 3, pp. 383-397.

Lave J., Wenger E. (1991) Situated learning. Legitimate peripheral participation. Cambridge University Press, Cambridge.

Llerena D. (1997) Coopération cognitives et modèles mentaux collectifs : outils de création et de diffusion de la connaissance. In: Économie de la Connaissance et Organisations. L'Harmattan, Paris.

Leroy F., Ramanantsoa B. (1997) Apprentissages organisationnels et création de connaissances dans le contexte d'une fusion-acquisition. In: Nonaka I., Takeuchi H. (Eds.), La connaissance créatrice. DeBoeck Université, Chap. 9, p. 270.

Nelson R.R., Winter S.G. (1982) An evolutionnary theory of economic change. Belknap, Harvard.

Nonaka I., Konno N. (1993) Chisiki Besu Soshiki (Knowledge Based Organization), Business Review, 41, pp. 59-73.

Nonaka I., Konno N. (1998) The concept of Ba: Building for knowledge creation, California Management Review, 40, No. 3, Spring.

Nonaka I., Takeuchi H. (1995) The knowledge creating company. Oxford University Press, Oxford.

Nonaka I., Takeuchi H. (1997) La connaissance créatrice. DeBoeck Université.

Orr J. (1987) Talking about machines: Social aspects of expertise, report for the intelligent systems laboratory. Xerox Palo Alto Research Center, Palo Alto, CA.

Polanyi M. (1958) Personal knowledge. Routledge, London.

Polanyi M. (1966) The tacit dimension. Garden City, New York.

Reix R. (1995) Savoir tacite et savoir formalisé dans l'entreprise, Revue Française de Gestion, No. 105 (special).

Richard J.F. (1995) Les activités mentales. Armand Colin, Paris.

Saviotti P.P. (1998) On the dynamics of appropriability, of tacit and codified knowledge, Research Policy, No. 26.

Snyder W.M., Wenger E.C. (2000) Communities of practice: The organizational frontier, Harvard Business Review, January-February.

Von Hippel E. (1988) The sources of innovation. MIT Press, Cambridge.

Wenger E. (1999) Communities of practice. Learning, meaning, and identity. Cambridge University Press, Cambridge.

Williamson O.E. (1994) Les institutions de l'économie. InterEditions, Paris.

Winter S.G. (1987) Knowledge and competences as strategic assets. In: Teece D.J. (Ed.), The competitive challenge. Cambridge Mass: Ballinger, p. 170. 